\title{
UMA BREVE ANÁLISE DA LEI № 12.403/2011 EM RELAÇÃO À PRISÃO EM FLAGRANTE NOS TERMOS DO CÓDIGO DE PROCESSO PENAL
}

\author{
Veronilde Oliveira de Almeida Junior; Fábio Ferreira Morong \\ Universidade do Oeste Paulista - UNOESTE, Curso de Direito, Presidente Prudente, SP. E-mail: \\ veronilde_junior@hotmail.com
}

\section{RESUMO}

A forma mais drástica de restringir a liberdade é por meio da prisão. Prisão essa que pode ser dividida em duas espécies: prisão como pena e prisão provisória. Dentro da espécie provisória encontramos o objeto de estudo deste trabalho que é a prisão em flagrante. O objetivo deste estudo é demonstrar as principais mudanças e seus efeitos relacionados à prisão em flagrante em decorrência das alterações que a lei no 12.403/2011. O método aplicado foi o dedutivo legal com a análise da doutrina, legislação nacional e jurisprudência pertinente ao tema. Conclui-se que as alterações implementadas por meio da Lei $n$. 12.403/2011, proporcionaram diferentes entendimentos sobre a atual natureza jurídica da prisão em flagrante, e que a adoção de uma ou outra interpretação proporciona uma implicação essencial na classificação do instituto como prisão provisória ou medida restritiva de liberdade.

Palavras-chave: Prisão em Flagrante; lei 12.403/2011; natureza jurídica.

\section{A BRIEF ANALYSIS OF LAW No. 12,403 / 2011 IN RELATION TO ARREST IN FLAGRANT UNDER THE CODE OF CRIMINAL PROCEDURE}

\begin{abstract}
The most drastic way to restrict freedom is through prison. This prison is able to be divided into two species: prison as a penalty and provisional prison. Inside the provisional species we find the main object of this research which is the arrest in flagrant. The purpose of this study is to demonstrate the main changes and their effects related to the arrest in flagrant as a result coming from the changes of the law $n=12403$ / 2011. The applied method was the legal deductive with a review of the doctrine, national legislation and jurisprudence related to the subject. We can conclude that the changes implemented through Law no. 12,403 / 2011 provided different understandings about the current legal nature of arrest in flagrant and the adoption of one interpretation or another one provides an essential implication in the classification of the institution as provisional arrest or restrictive measure of freedom.
\end{abstract}

Keywords: Prison in Flagrante; Law 12,403 / 2011; Legal nature. 


\section{INTRODUÇÃO}

A liberdade é um dos direitos fundamentais do homem, contudo, ela não é um direito absoluto eis que é uma medida excepcional. A forma mais drástica de restringir a liberdade é por meio da prisão. Prisão essa que pode ser dividida em duas espécies: prisão como pena e prisão provisória, senda está ultima parte do objeto do presente estudo.

Dentro da espécie provisória encontra-se a prisão em flagrante, que é medida restritiva de liberdade, de natureza cautelar e caráter eminentemente administrativo, que não exige ordem escrita do juiz, porque o fato ocorre de forma súbita (art. 5o, inciso LXI da CF).

A lei $\mathrm{n}$ - 12.403/2011 trouxe mudanças significativas que de fato ocasionaram algumas divergências doutrinárias a respeito do instituto em discussão, de modo que, por um lado, seria uma medida restritiva de liberdade, de caráter administrativo, inexistindo dessa maneira a restrição jurisdicional em sua realização; e por outro, a lei não haveria modificado a essência da prisão em flagrante, que manteria sua natureza de prisão provisória, sob o intuito essencial de resguardar o bem jurídico atingido pela conduta criminosa.

O objetivo deste estudo é demonstrar as principais mudanças e seus efeitos relacionados à prisão em flagrante em decorrência das alterações que a lei no 12.403/ 2011

\section{METODOLOGIA}

Para elaboração do presente trabalho utilizou-se da metodologia da pesquisa bibliográfica, utilizando materiais como doutrinas, legislação nacional e jurisprudências, que são pertinentes para o objeto em estudo. O método dedutivo também fora utilizado para sistematizar os dados coletados a fim de cumprir o objetivo proposto.

\section{RESULTADOS}

Segundo dados coletados do Instituto 'Sou da Paz', em parceria com a Secretaria de Segurança do Estado de São Paulo, entre os anos de 2009 e 2011 haviam sido realizadas 305.006 mil prisões em flagrante só no Estado de São Paulo (2012, p.08). Esses números reforçam a tese de que a prisão em flagrante desempenha importante papel no nosso ordenamento jurídico.

Desse modo, apresenta a doutrina:

A prisão em flagrante, portanto, cumpre importantíssima missão, cuidando da diminuição dos efeitos da ação criminosa, quando não do seu completo afastamento (dos efeitos), bem como da coleta imediata da prova, para o cabal esclarecimento dos fatos. (OLIVEIRA, 2011, p. 537)

Essa 'missão' ou objetivos delimitados da prisão em flagrante justificam a temporalidade curta de sua existência ( 24 horas). A lógica auxilia no entendimento de que esgotada sua função, não seria coerente a manutenção da mesma.

Outrossim, como novidade, a partir da modificação da redação do artigo 310 instituído pela Lei 12.403 de 2011, a norma tornou obrigatória à tomada pelo juiz das providências expressas nos incisos do aludido artigo 310 do Código de Processo Penal (Brasil,1941). Ou seja, as inovações introduzidas no Código de Processo Penal pela Lei 12.403, de 4 de maio de 2011, impuseram ao juiz a obrigação de converter em prisão preventiva a prisão em flagrante delito, somente quando apurada a impossibilidade de relaxamento ou concessão de liberdade provisória, com ou sem medida cautelar diversa da prisão. 
Por sua vez, é curial salientar que tais inovações serviram também como fundamento para a constituição da resolução no 213 de 2015 do Conselho Nacional de Justiça (CNJ) a qual detalha o procedimento para apresentação de presos em flagrante à autoridade judicial competente e possui dois protocolos de atuação, o primeiro para verificar a legalidade e necessidade da prisão, e o segundo sobre os procedimentos para apuração de denúncias de tortura. (CONSELHO NACIONAL DE JUSTIÇA (CNJ), 2018).

\section{DISCUSSÃO}

Como já visto, A liberdade é um dos direitos fundamentais do homem, contudo, ela não é um direito absoluto eis que é uma medida excepcional. Pois bem, um dos principais pensadores ingleses, John Locke (1632-1704), afirmava que o homem, independentemente de qualquer convenção social, possuía como direitos fundamentais o direito à vida, a liberdade e a propriedade. Como decorrência possuía também a faculdade de fazer cessar qualquer ameaça de lesão a esses direitos. Segundo ele, o Estado, em decorrência do contrato social, teria para com os seus membros o dever de "preservar a vida, a liberdade e a posse de que gozam tais membros" (LOCKE, 2011, p.114).

Assim, admitindo a liberdade como direito fundamental, entende-se que o estado de liberdade seja a regra e que toda forma de restrição deva ser aceita exclusivamente em situação excepcional. Nasce daí um desafio para o legislador que, nas palavras de Stuart Mill (2011, p.43) seria " $\{. .$.$\} produzir o ajuste adequado entre a independência individual e o$ controle social".

Nesse sentido, segundo Cesare Beccaria:

Só a necessidade constrange os homens a ceder uma parte de sua liberdade; daí resulta que cada um só consente em pôr no depósito comum a menor porção possível dela, isto é, precisamente o que era preciso para empenhar os outros em mantê-lo na posse do resto (BECCARIA, 2006, p.10)

Por sua vez, a Constituição Federal de 1988 (BRASIL, 1988) reforça o compromisso com a liberdade nos moldes de seu artigo 5ㅇ, caput da CF, que faz menção a garantia da inviolabilidade à liberdade. Contudo, o mesmo artigo posteriormente assevera, dentro de certo processo, a restrição da liberdade quando em seu artigo LIV, que dispõe que: "ninguém será privado da liberdade ou de seus bens sem o devido processo legal" (BRASIL,1988). Esse posicionamento constitucional que em um primeiro momento pode parecer uma incoerência, é na verdade reflexo do reconhecimento de que nenhum direito é absoluto.

Existe, porém, um maior cuidado quando se pretende restringir o acesso a esses direitos. Na obra clássica 'Dos Delitos e das Penas' de Cessare Beccaria fica expressa essa preocupação quando o autor afirma: "\{...\} a lei deve estabelecer, de maneira fixa, por que indícios de delito um acusado pode ser preso e submetido a interrogatório" (2006, p. 14).

Assim, a liberdade é a regra e qualquer forma de restrição deve ser em caráter excepcional.

De outro lado, em relação contrária, a prisão é uma restrição da liberdade. É uma exceção. Por isso mesmo só pode ser decretada se atendidos os requisitos legais, nos termos do artigo 5ㅇ, inc. LXI da CF que assim descreve:

“Art. 5o, LXI - ninguém será preso senão em flagrante delito ou por ordem escrita e fundamentada de autoridade judiciária competente, salvo nos casos de transgressão militar ou crime propriamente militar, definidos em lei;" (BRASIL,1988) 
Entretanto, antes de se discutir a respeito do entendimento atual da prisão, no caso especifico sobre a prisão, é relevante a compreensão de todo o caminho histórico que a referida modalidade de prisão percorreu no nosso ordenamento jurídico. Nesse sentido pondera Freyesleben:

O instituto da prisão em flagrante delito existe desde remotos tempos, impostos pela necessidade. $O$ seu aparecimento nas leis de todos os países explica-se, fundamentalmente, pela consideração de que profundo alarma social produziria o ver cometeram-se crimes sem a possibilidade de pronta repressão, iniciada pela interferência dos circunstantes. (FREYESLEBEN, 1997, p.51)

Destarte, se a necessidade impôs a criação do instituto da prisão em flagrante no ordenamento jurídico em todos os países, no Brasil não seria diferente.

Observando o aspecto temporal, nota-se que antes de o país tornar-se independente em 1822, vigorava a lei portuguesa que em suas Ordenações Filipinas já mencionava casos de aplicação da prisão em flagrante. Decretada em 1603, durante o reinado de Felipe II, as Ordenações Filipinas ajudaram a regrar de forma mais clara a aplicação do instituto. Desse modo, entende a doutrina que tal lei:

$\{\ldots\}$ Determinou que fossem presos como em flagrante aqueles delinquentes que houvessem fugido depois de cometido o crime, uma vez que a luta tivesse acabado pouco tempo antes do aparecimento da autoridade, e esta, recebendo informação exata da direção seguida pelos delinquentes, fosse à sua procura sem interrupção. (LEÃO, 2004, p.16)

Por sua vez, o mandamento constitucional divide-se em duas espécies de prisão. Uma derivada da imposição de pena que "é a que ocorre após o trânsito em julgado da sentença condenatória" (OLIVEIRA, 2009, p.157). A outra é a provisória, cautelar ou processual, sendo a primeira marcada pelo seu caráter punitivo, cujo qual não se encontra na segunda.

Em relação à prisão provisória, a doutrina a assim pondera:

Trata-se de prisão de natureza puramente processual, imposta com finalidade cautelar, destinada a assegurar o bom desempenho da investigação criminal, do processo penal ou da futura execução da pena, ou ainda a impedir que, solto, o sujeito Curso de Processo Penal continue praticando delitos. É imposta apenas para garantir que o processo atinja seus fins. Seu caráter é auxiliar e sua razão de ser é viabilizar a correta e eficaz persecução penal. Nada tem que ver com a gravidade da acusação por si só, tampouco com o clamor popular, mas com a satisfação de necessidades acautelatórias da investigação criminal e respectivo processo. (CAPEZ, 2012 p.301)

Realizadas as distinções, ressalta-se que a prisão provisória divide-se ainda em três subespécies: flagrante delito, prisão preventiva e prisão provisória. Com efeito, apenas nas duas últimas o sujeito poderá permanecer preso.

Tal diferença nas prisões realizadas em flagrante delito é devida ao fato de que recebido o auto da prisão de flagrante o juiz deverá fundamentadamente optar por relaxar a prisão ilegal, conceder liberdade provisória ou converter a prisão em flagrante em preventiva, conforme disposto no artigo 310 do Código de Processo Penal (BRASIL, 1941). Entende-se que o prazo para essas medidas seja o prazo de 24 horas e, ressalta-se que tais mudanças foram operadas basicamente a partir da entrada em vigor da Lei 12.403/11. 
Para Júlio Fabrini Mirabete “(...) a possibilidade de se prender alguém em flagrante delito é um sistema de autodefesa da sociedade, derivada da necessidade sócia de fazer cessar a prática criminosa e a perturbação da ordem jurídica" (MIRABETE, 1997, p.370).

Acrescente-se que a prisão em flagrante pode apresentar várias espécies ou hipóteses, sendo elas: flagrante próprio, flagrante impróprio, flagrante presumido, flagrante preparado ou provocado, flagrante esperado, flagrante prorrogado ou retardado e flagrante forjado.

Em relação ao sujeito que efetiva a prisão pode ainda ser dividido em flagrante compulsório e facultativo. Diz-se próprio ou real quando o agente é encontrado cometendo ação delituosa ou acaba de cometê-la. Esse entendimento encontra expressão legal no artigo 302, incisos I e II do Código de Processo Penal (BRASIL, 1941). Por impróprio entende-se a situação de flagrante em que o agente é perseguido logo após a cometer o ilícito, ocorrendo a situação em que o agente possa ser presumido como autor. Tal hipótese está prevista no artigo 302, III do CPP. (BRASIL, 1941)

O flagrante presumido é aquele expresso no artigo 302, IV do CPP, E nessa situação o agente é encontrado logo depois de cometer o ilícito com instrumentos, armas, objetos ou papéis que façam presumir ser o autor da infração. O Flagrante retardado ou prorrogado é uma hipótese não prevista no Código de Processo Penal. Tal hipótese está prevista no artigo 2ํㅡ, II, da Lei n. 9.034/95.

Flávio Cardoso Oliveira (2009, p.162) exemplifica tal hipótese: "policial identifica atos criminosos de uma organização, mas prevê a possibilidade de prender posteriormente com prova mais contundente, retardando, então, sua intervenção".

Além dessas espécies legais, ou seja, previstas em lei, Existem também espécies ilegais de flagrante. Nessa categoria se enquadra o flagrante preparado ou provocado em que um terceiro induz o agente a praticar um ilícito justamente para prendê-lo. Nesse caso a vontade do agente está viciada e pelas circunstâncias torna o crime impossível.

As mudanças que a Lei $12.403-2011$ acarretou na prisão em flagrante também são discutidas por Capez (2012, p.299):

A prisão em flagrante perdeu seu caráter de prisão provisória. Ninguém mais responde
a um processo criminal por estar preso em flagrante. Em outras palavras, o sujeito é
preso em razão do estado de flagrância, mas não permanece nessa condição por mais
muito tempo. Lavrado o auto, a autoridade policial deverá remetê-lo ao juiz
competente no prazo máximo de vinte e quatro horas a partir da prisão. O juiz, então,
não se limitará mais a analisar a regularidade formal do flagrante, devendo justificar se
é caso de convertê-lo em preventiva. Não havendo fundamento para a prisão
preventiva, o agente deverá ser solto e responder ao processo em liberdade. Antes, a
pessoa presa em flagrante requeria a liberdade provisória e aguardava a concessão do
benefício. A decisão era postergada muitas vezes até o final do processo-audiência,
para só então ser analisada.

Denota-se que as alterações discutidas são importantes em relação à interpretação doutrinária e jurisprudencial a ser adotada no sentido de adequação à real intenção do legislador quando institui a aludida lei, o que certamente refletirá nos aspectos práticos de cada caso concreto.

\section{CONCLUSÃO}

Entende-se que a lei n.12.403 de 4 de julho de 2011 operou algumas modificações significativas na legislação processual penal que implicaram diretamente na interpretação jurídica e na prática da prisão em flagrante. Restou evidente um par de entendimentos e 
interpretações diversas, que certamente a posição predominante será consolidada no decorrer do tempo.

O primeiro entendimento defende que o flagrante se torna, a partir da lei, uma medida restritiva de liberdade, de caráter administrativo, inexistindo dessa maneira a restrição jurisdicional em sua realização. Já o outro, prega que a lei não haveria modificado a essência da prisão em flagrante e que mantém sua natureza de prisão provisória, sob o intuito essencial de resguardar o bem jurídico atingido pela conduta criminosa.

Portanto, conclui-se que as alterações implementadas por meio da Lei n. 12.403/2011, proporcionaram diferentes entendimentos sobre a atual natureza jurídica da prisão em flagrante, e que a adoção de uma ou outra interpretação proporciona uma implicação essencial na classificação do instituto como prisão provisória ou medida restritiva de liberdade.

\section{REFERÊNCIAS}

BECCARIA, Cesare. Dos delitos e das penas. Trad. Nelson Jahr Garcia. São Paulo: Martin Claret, 2006.

BRASIL. Código de processo penal. Decreto-lei no 3689, de 3 de outubro de 1941. Disponível em: <http: //www.planalto.gov.br/ccivil_03/decreto-lei/Del3689.htm . > Acesso em: 16 out. 2016.

BRASIL. Constituição (1988). Constituição da República Federativa do Brasil. Brasília: Senado Federal, 1988.

CAPEZ, Fernando. Curso de processo penal. 19.ed. São Paulo: Saraiva, 2012.

CONSELHO NACIONAL DE JUSTIÇA. Resolução no 213, de 15 de dezembro de 2015. Dispõe sobre a apresentação de toda pessoa presa à autoridade judicial no prazo de 24 horas. Disponível em:< http://www.cnj.jus.br/busca-atos-adm?documento=3059

>. Acesso em: 10 jul. 2018;

FREYESLEBEN, Marcio Luís Chila. A Prisão Provisória no CPPM. Belo Horizonte: Del Rey, 1997.

INSTITUTO SOU DA PAZ. Relatório da Pesquisa Prisões em Flagrante na cidade de São Paulo. $2012 . \quad$ Disponivel em: <http://www.soudapaz.org/upload/pdf/justica_prisoesflagrante_pesquisa_web.> Acesso em: 16 out. 2016.

LEÃO, Paula Cafiero. Prisão em flagrante. 2004.76f. Monografia (graduação). Faculdades Metropolitanas Unidas, São Paulo-SP.

LOCKE, John. Segundo tratado sobre o Governo. Trad. Alex Marins. São Paulo: Martin Claret, 2011.

MILL, John Stuart. Sobre a liberdade. Trad. Ari R. Tank Brito. São Paulo: Hedra, 2010.

MIRABETE, Julio Fabrini. Código de Processo Penal Interpretado. 5. ed. São Paulo: Atlas, 1997. 
OLIVEIRA, Flávio Cardoso de. Direito processual penal, 5. São Paulo: Saraiva, 2009.

OLIVEIRA, Eugênio Pacelli de. Curso de processo penal. 15.ed. Rio de Janeiro: Editora Lumen Juris, 2011.

TÁVORA, Nestor; ALENCAR, Rosimar Rodrigues. Curso de direito processual penal. 6 ed. Salvador: Juspodivm, 2011. 